\title{
Chewa Language
}

National Cancer Institute

\section{Source}

National Cancer Institute. Chewa Language. NCI Thesaurus. Code C154062.

A Niger-Congo Bantu language native to Zambia, Malawi, Mozambique, and Zimbabwe. 